\title{
Fracture mechanics of pseudoelastic NiTi alloys: review of the research activities carried out at University of Calabria
}

\author{
C. Maletta, F. Furgiuele, E. Sgambitterra \\ Dept. of Mechanical Engineering, University of Calabria, 87036 Rende (CS), Italy. \\ carmine.maletta@unical.it
}

\begin{abstract}
This paper reports a brief review of the research activities on fracture mechanics of nickel-titanium based shape memory alloys carried out at University of Calabria. In fact, this class of metallic alloys show a unusual fracture response due to the reversible stress-induced and thermally phase transition mechanisms occurring in the crack tip region as a consequence of the highly localized stresses. The paper illustrates the main results concerning numerical, analytical and experimental research activities carried out by using commercial NiTi based pseudoelastic alloys. Furthermore, the effect of several thermo-mechanical loading conditions on the fracture properties of NiTi alloys are illustrated.
\end{abstract}

KEYWORDS. Shape Memory alloys; Stress-Induced Martensitic transformation; Fracture mechanics.

\section{INTRODUCTION}

$\mathrm{N}$ ickel-Titanium alloys (NiTi) are the most useful shape memory alloys, because they combine high recovery capabilities with good mechanical performances and biocompatibility. These alloys are also known as Nitinol, which stands for Nickel Titanium Naval Ordnance Laboratory (White Oak, Maryland), where in 1961 their shape memory capabilities were discovered. After their discovery NiTi alloys have attracted the interest of the scientific and engineering community due to their unique properties, namely pseudoelastic effect (PE) and shape memory effect (SME). These functional properties are due to a reversible solid state phase transformation between a parent phase (B2 austenite) and a product phase (B19' - martensite), the so called thermoelastic martensitic transformation (TMT), which can be activated either by temperature (thermally-induced martensitic transformation, TIM) or by applied stress (stressinduced martensitic transformation, SIM) [1]. As a result of these microstructural changes, NiTi alloys are able to recover high values of mechanical deformations (up to $12 \%$ ), by either heating the material above the characteristic transition temperatures (SME) or by removing the mechanical load (PE). However, due to their unique microstructural evolutions elastic and elastic plastic theories cannot be applied to study the mechanical response of NiTi alloys and, consequently, adhoc models should be developed which take into account the thermally-induced and/or stress induced transformations. In particular, it is widely accepted by the scientific community that crack formation and propagation are significantly affected by the phase transitions mechanisms and, consequently, NiTi alloys exhibit unusual fatigue and fracture responses with respect to common metals. This topic is of great technological and scientific interest as demonstrated by several recent experimental studies, which have been aimed to evaluate the evolution of cracks under both static [2-8] and cyclic loading conditions [9-12]. Furthermore, several numerical studies have been carried out, by using standard finite element codes and plasticity concepts [13-15] as well as by special constitutive models for SMAs [16-17]. Finally, some analytical models have been proposed recently [18-27], which are mainly based on modified linear elastic fracture mechanics concepts.

In the present paper a review of the research activities on fracture mechanics of NiTi alloys, carried out at the Department of Mechanical Engineering at University of Calabria (Italy), is illustrated. The stress-induced martensitic transformation occurring in the crack-tip region, as a consequence of the high values of local stresses, and the resulting stress distribution 
have been analyzed by numerical simulations [15], analytical modeling [23-26] and experimental measurements [7-8]. In particular, Finite Element (FE) simulations have been carried out, by using commercial software codes and standard nonlinear plasticity analyses, i.e. by modeling the monotonic stress-strain of SMAs as a plastic-like behavior. Preliminary FE studies have been carried out in [15], where Single Edge Crack specimens (SEC) have been analyzed by two-dimensional plane stress FE analyses. In this study the crack tip transformation mechanisms have been analyzed together with their effects on the stress distribution. In addition, a first attempt to model these phase transition mechanisms by modified Linear Elastic Fracture Mechanics (LEFM) concepts is illustrated. Subsequently, an analytical model has been proposed in [23] based on the Irwin's correction of LEFM [28] which allows to simulate both the stress-induced crack-tip transformation region and the resulting stress distribution under plane stress conditions. In addition, numerical simulations have been carried out by considering a central crack in a plate subjected to mode I loading conditions; systematic comparison between numerical and analytical results have been carried out and good agreements have been observed. Finally, the effects of thermo-mechanical parameters and loading conditions have been analyzed.

The model has been subsequently updated in [24] to analyze both plane stress and plane strain conditions, by considering a tri-axial constraint factor for phase transition mechanisms. Furthermore, the model prediction have been compared with experimental literature data [5] concerning synchrotron X-ray microdiffraction experiments of miniature CT specimens.

The reference analytical model has been also used to define possible fracture control parameters for SMAs in [25] based on the definition of Stress Intensity Factor in LEFM. Finally, the reference model has been recently modified in [26] to overcome one of the basic limitation, i.e. the assumption of constant stress transformation. In particular, the stress-strain response is modeled as a tri-linear material with a generic slope of the transformation plateau.

Experimental tests have been carried out in [7] for a comparative study between base and laser welded materials, by using SEC specimens obtained from a commercial pseudoelastic NiTi sheet (Type S, Memry, USA). However only the notch strength was calculated for the comparative analysis, and no further considerations have been made about the complex fracture mechanisms in SMAs. More recently the effects of temperature, within the stress-induced transformation regime, in SEC specimens have been analyzed [8], by experimental measurements and analytical studies. The tests were carried out at different values of the testing temperature the critical values of the stress intensity factor were computed, based on LEFM theory on the reference analytical model [25].

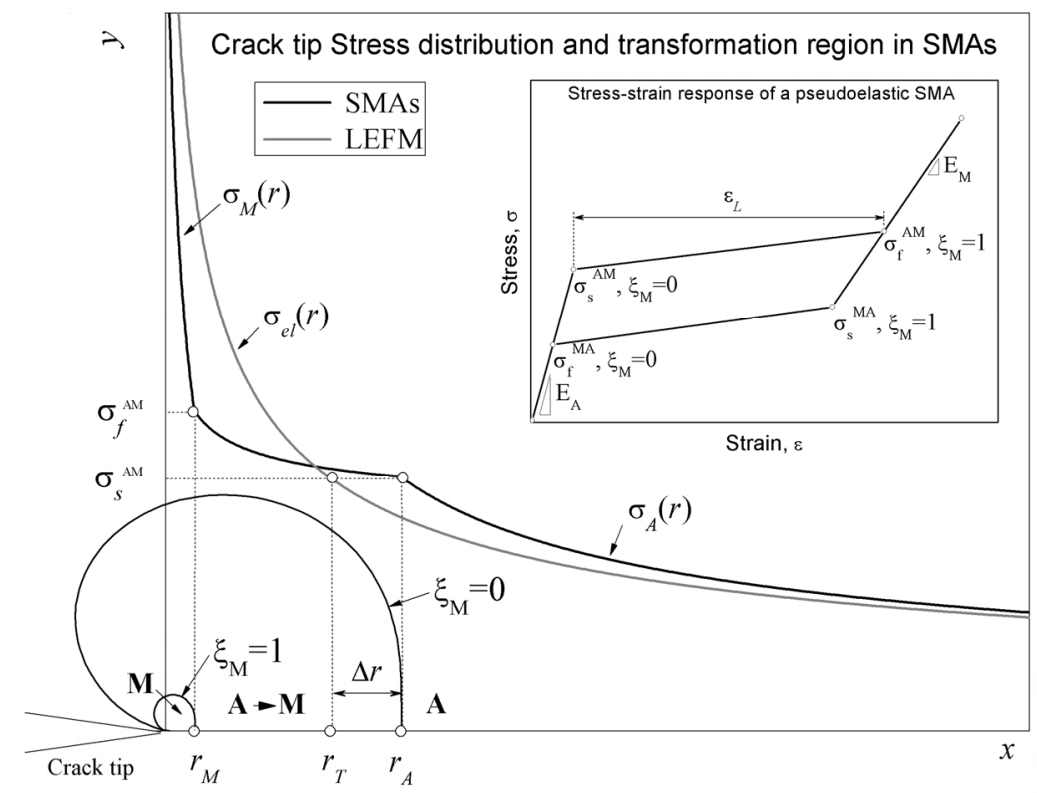

Figure 1: Schematic depiction of the crack-tip stress distribution and transformation region in pseudoelastic NiTi SMAs.

\section{FRACTURE MECHANICS OF SMAS: BASIC FEATURES}

7 he high values of local stresses in the crack tip region of pseudoelastic NiTi alloys cause a stress-induced martensitic transformation and, consequently, marked differences are observed with respect to common linear elastic or elastic plastic materials as schematically shown in Fig. 1. In fact, due to this microstructural evolution 
three different regions are observed in the crack tip region: the austenitic untransformed region (A), the phase transformation region $(\mathrm{A} \rightarrow \mathrm{M})$ and the fully transformed martensitic region $(\mathrm{M})$.

The size of the fully transformed martensitic region $\left(\xi_{M}=1\right)$ and of the transformation region $\left(0 \leq \xi_{M} \leq 1\right)$, along the plane of the crack, are identified by the radii $r_{M}$ and $r_{A}$, namely martensitic and austenitic radii, respectively. In addition, due to the large transformation strain occurring at the very crack tip, a marked non-linearity and a complex stress distribution are observed, as schematically shown in Fig. 1, with respect to common metallic alloys. The figure also illustrates a schematic depiction of the stress-strain response of a pseudoelastic alloy together with the main mechanical parameters: the direct transformation stresses, $\sigma_{S}^{A M}$ and $\sigma_{f}^{A M}$, the transformation strain, $\varepsilon_{L}$, and the effective Young's moduli of austenite, $E_{A}$, and martensite, $E_{M}$. The transformation strain and the Young's moduli are considered as material constants while the transformation stresses can be expressed as a function of the temperature, $T$, according to the Clausius-Clapeyron relation:

$$
\begin{gathered}
\sigma_{S}^{A M}=\sigma_{S 0}^{A M}+b_{M}\left(T-T_{0}\right) \\
\sigma_{f}^{A M}=\sigma_{f 0}^{A M}+b_{M}\left(T-T_{0}\right)
\end{gathered}
$$

where $\sigma_{S 0}^{A M}$ and $\sigma_{f 0}^{A M}$ are the transformation stresses at the reference temperature $T_{0}$ and $b_{M}$ is a material constant.

\section{NUMERICAL MODELING}

7 he crack tip stress distribution and transformation region in pseudoelastic SMAs have been studied by Finite Element (FE) simulations carried out by using commercial software codes and standard non-linear plasticity analyses. In fact, monotonic loads to fracture are generally applied to specimens for toughness measurements and, consequently, the stress-strain hysteretic behavior, observed during loading-unloading cycles, is not taken into account. Due to this reason the monotonic nonlinear behavior of SMAs is treated as a plastic-like response.

Preliminary FE studies have been carried out in [15], where Single Edge Crack specimens (SEC) have been analyzed by two-dimensional plane stress FE analyses, carried out with the commercial finite element code MSC Marc ${ }^{\mathbb{B}}$. The geometry of the SEC specimen is illustrated in Fig. 2a, while the corresponding FE model is illustrated in Fig. 2b together with an highlight of the crack tip. Particularly fine mesh has been adopted to model the crack tip region in order to describe the high stress gradient as well as for an accurate prediction of the non-linear stress distribution due to the stress induced transformation mechanisms $(\mathrm{A} \rightarrow \mathrm{M})$.

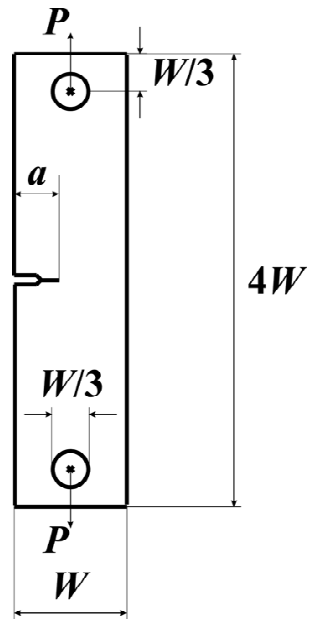

a)

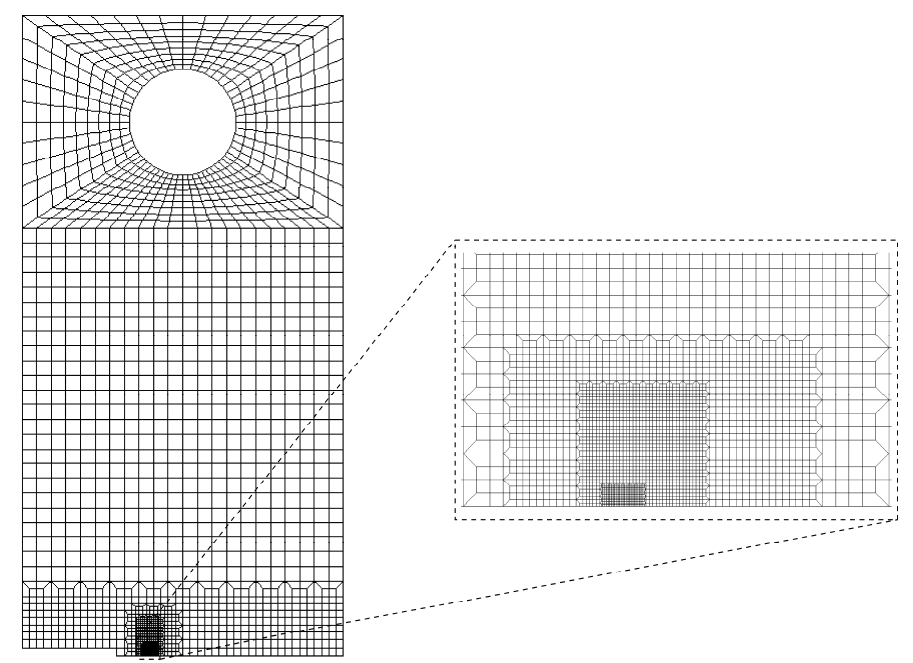

b)

Figure 2: SEC specimen: a) geometry and b) FE model with an highlight of the crack tip [15] 
Several simulations have been carried out for different thermo-mechanical loading conditions as well as by varying the main thermo-mechanical parameters of the alloy, in terms of transformation strain $\left(\varepsilon_{L}\right)$ and transformation stresses $\left(\sigma_{S}^{A M}\right.$ and $\left.\sigma_{f}^{A M}\right)$. As an example Fig. 2a illustrates the transformation region near the crack tip, i.e. the contours of the martensite fraction $\xi_{M}$, while and the effects of the testing temperature $T$ on the transformation radii, $r_{M}$ and $r_{A}$, are illustrated in Fig. 3.b. These results have been obtained under a remote tensile stress $\sigma^{\infty}=20.5 \mathrm{MPa}$ for a SMA with Young's moduli $E_{A}=39 \mathrm{GPa}$ and $E_{M}=20 \mathrm{GPa}$. The figure shows that both $r_{M}$ and $r_{A}$ decrease with increasing the temperature $T$; resulting in an overall reduction of the transformation zone.

These preliminary results have been confirmed by subsequent numerical simulations carried out in [23] and in [8] where systematic comparison with the estimates of a novel analytical approach have been carried out, as illustrated in the following section.

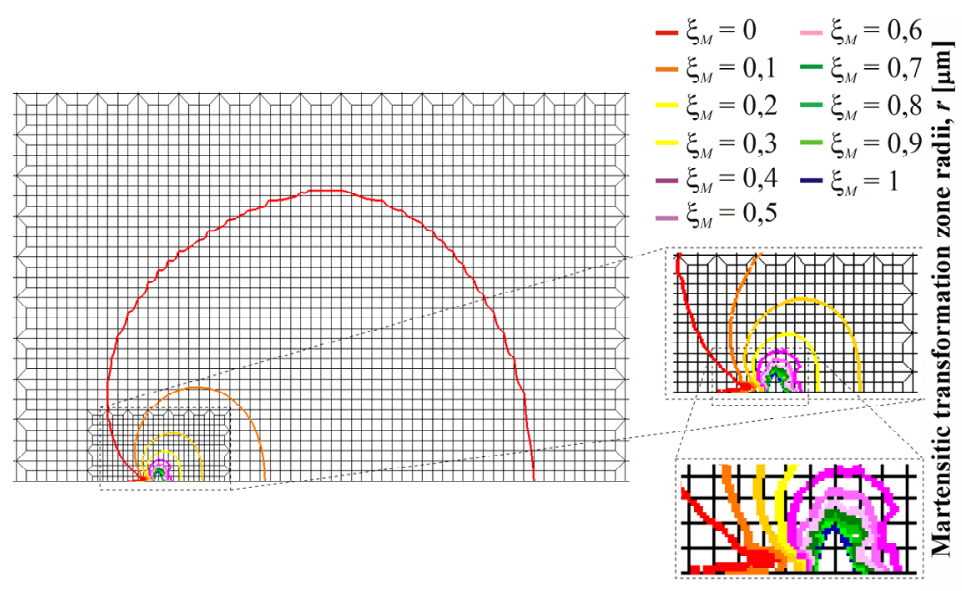

a)

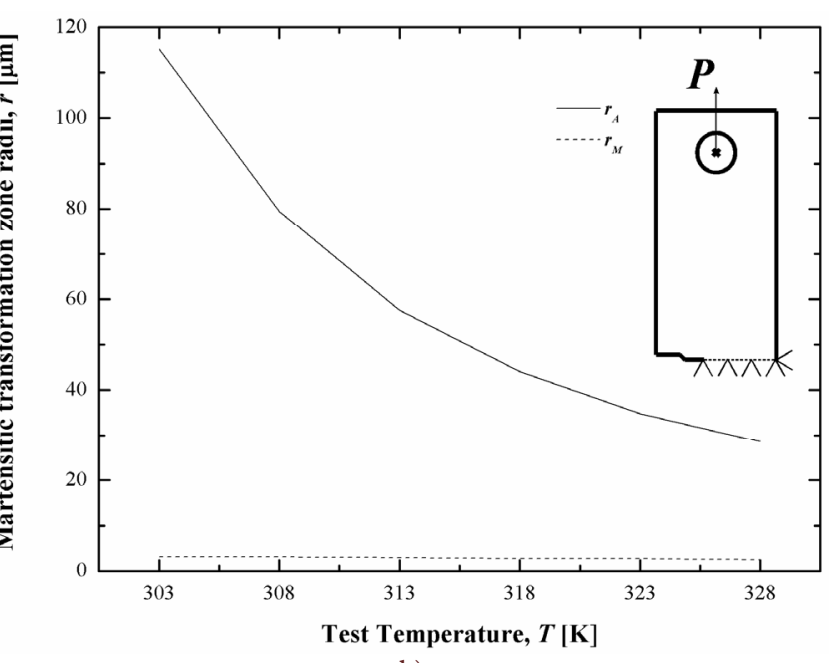

b)

Figure 3: FE results of the crack tip transformation behavior in a pseudoelastic SMA: a) contours of the martensite fraction $\left(\xi_{M}\right)$ and b) transformation radii $\left(r_{M}\right.$ and $\left.r_{A}\right)$ as a function of the testing temperature [15].

\section{ANALYTiCAL Modeling}

A novel analytical approach has been developed recently [23], which is based on a modified Irwin's correction [28] of Linear Elastic Fracture Mechanics (LEFM). In particular, the model allows to describe the crack tip stress distribution and transformation region in pseudoelastic NiTi alloys under plane stress conditions. The model has been subsequently improved in [24] to describe both plane stress and plane strain conditions while in [25] two fracture control parameters have been proposed, based on modified Stress Intensity Factors (SIF). Finally, a new version of the model has been developed in [26] to overcome a limitation of the reference model, i.e. the assumption of constant stress transformation.

For the sake of completeness and readability the basic expression of the stress components and of the transformation radii, $r_{M}$ and $r_{A}$, are given in the following but complete and detailed descriptions of the model are reported in the reference papers [23-24]. Eq. 3 gives the expression of the principal stress components along the plane of the crack $(\vartheta=0)$, in the austenitic region:

$$
\sigma_{A 1}(r)=\sigma_{A 2}(r)=\frac{K_{l e}}{\sqrt{2 \pi(r-\Delta r)}}
$$

The stress equation $\sigma_{A}$ is obtained by a modified Irwin's correction [28] of the LEFM, i.e. by using effective crack length and SIF, namely $a_{e}$ and $K_{I e}$ :

$$
a_{e}=a+\Delta r
$$




$$
K_{I e}=\sigma^{\infty} \sqrt{\pi a_{e}}
$$

where the distance $\Delta \mathrm{r}$ is given by:

$$
\Delta r=r_{A}+r^{*}
$$

with

$$
r^{*}=\frac{1}{2 \pi}\left(\frac{K_{I}}{f_{t c} \sigma^{A M}}\right)
$$

where $\sigma^{A M}$ is the direct $\mathrm{A} \rightarrow \mathrm{M}$ transformation stress and it is assumed to be constant $\left(\sigma^{A M}=\sigma_{s}^{A M}=\sigma_{f}^{A M}\right) ; f_{t c}$ can be regarded as a transformation constraint factor, i.e. it is defined based on the plastic constraint factor in LEFM [29], and varies in the range between 1 and $(1-2 v)^{-1}$, with the lower and upper bounds corresponding to the plane stress and plane strain conditions, respectively. The stress distribution in the martensitic region can be obtained by modified relations for bilinear materials and it is given by the following equation:

$$
\sigma_{M 1}(r)=\sigma_{M 2}(r)=\frac{1}{2 \kappa+f_{t c}^{-1}\left(\alpha^{-1}-1\right)}\left[2 \kappa \frac{K_{I e}}{\sqrt{2 \pi r}}+\left(\alpha^{-1}-1\right) \sigma^{A M}-2 \chi \varepsilon_{L} E_{A}\right]
$$

where $\alpha$ represents the Young's modulus ratio $\left(\alpha=E_{M} / E_{A}\right)$ while $\kappa=(1-v)$ and $\chi=1 / 2$ for plane stress and $\kappa=(1+v)(1-2 v)$ and $\chi=\sqrt{3} / 2$ under plane strain conditions. The martensitic radius $r_{M}$, can be calculated by using the condition $\sigma_{M 1}\left(r_{M}\right)=f_{t c} \sigma^{A M}$ :

$$
r_{M}=\frac{1}{2 \pi}\left[\frac{2 \kappa K_{I e}}{2 f_{t c} \kappa \sigma^{A M}+2 \chi \varepsilon_{L} E_{A}}\right]^{2}
$$

The austenitic radius $r_{A}$ can be calculated by imposing the equilibrium condition at the crack tip, as described in [23], and, thus, the following relation can be obtained:

$$
r_{A}=2 r^{*}-\frac{1}{\pi}\left(\frac{\kappa K_{I e}}{\sigma^{A M}}\right)^{2} \frac{1}{\left(2 f_{t c} \kappa+\left(\alpha^{-1}-1\right)\right)} \frac{1}{f_{t c} \kappa+\chi \varepsilon_{L} E_{A} / \sigma^{A M}}
$$

Several analysis have been carried out in [23] by considering a central crack with length $2 a$ in an infinite plate subjected to mode I loading conditions. In particular, the effects of the main thermo-mechanical parameters of the alloy, in terms of the transformation strain $\left(\varepsilon_{L}\right)$ and stress $\left(\sigma^{A M}\right)$, on the crack tip stress distribution and transformation region have been analyzed, as illustrated in Fig. 4.

In addition, comparisons with FE results are also illustrated in the figure and good agreements are observed. In particular, Fig. 4.a illustrates the crack tip stress distribution for a SMA with Young's moduli $E_{A}=50 G P a$ and $E_{M}=25 G P a$, while Fig. 4.b illustrates the values of $r_{A} / a$ and $r_{M} / a$ as a function of the transformation strain $\left(\varepsilon_{L}\right)$ for two values of the transformation stress $\left(\sigma^{A M}\right)$. A marked decrease of $r_{A} / a$ is clearly observed together with a decrease of $r_{M} / a$ when increasing the transformation stress $\sigma^{A M}$, as a direct consequence of the increased values of local stresses near the crack tip in the austenitic region. Furthermore, a slight increase of $r_{A} / a$ together with a reduction of $r_{M} / a$ is observed when increasing the transformation strain and these effects become more evident when reducing the transformation stress.

The estimates of the analytical model on crack tip stress-induced transformation have been also compared with experimental literature data in [24]; these latter have been obtained by synchrotron X-ray microdiffraction experiments of a miniature CT specimen, under opening mode conditions with a constant load $P=2860 \mathrm{~N}$ and a crack length-to-width ratio $a / W=0.55$ [5]. In particular, in Fig. 5 the contours of the austenitic radius, $r_{A}$, under both plane stress and plane strain conditions, are compared with the microdiffraction patterns. The experimentally observed transformation region is between plane stress and plane strain contours and this is the expected result as X-ray observations represents volume- 
averaged data along the specimen thickness (i.e. between plane stress at the specimen surfaces and plane strain in the center). Furthermore, the martensitic radius $r_{M}$ is not illustrated as it is about one order of magnitude less than austenitic radius $r_{A}$ and it is not illustrated in the microdiffraction patterns, which show only the region with 30-40\% volume fraction of martensite (B19’).

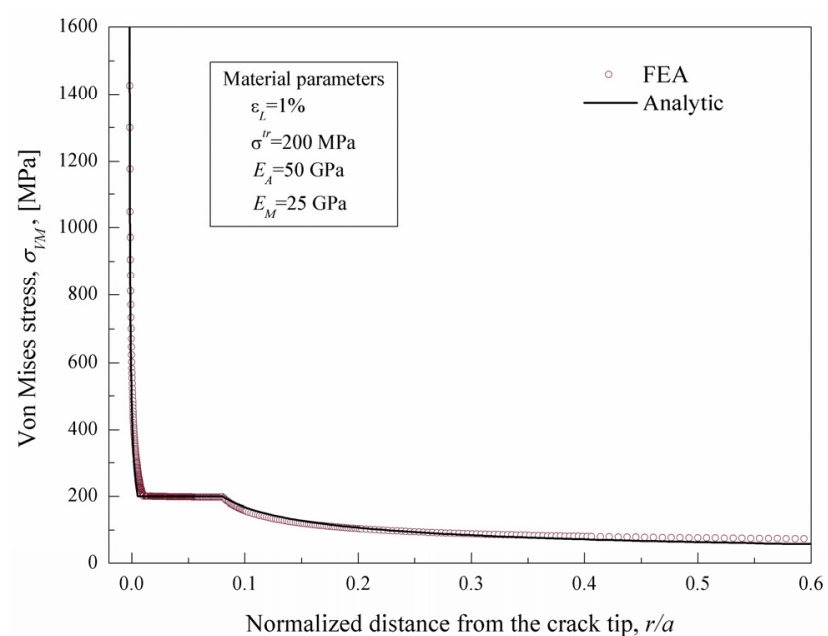

a)

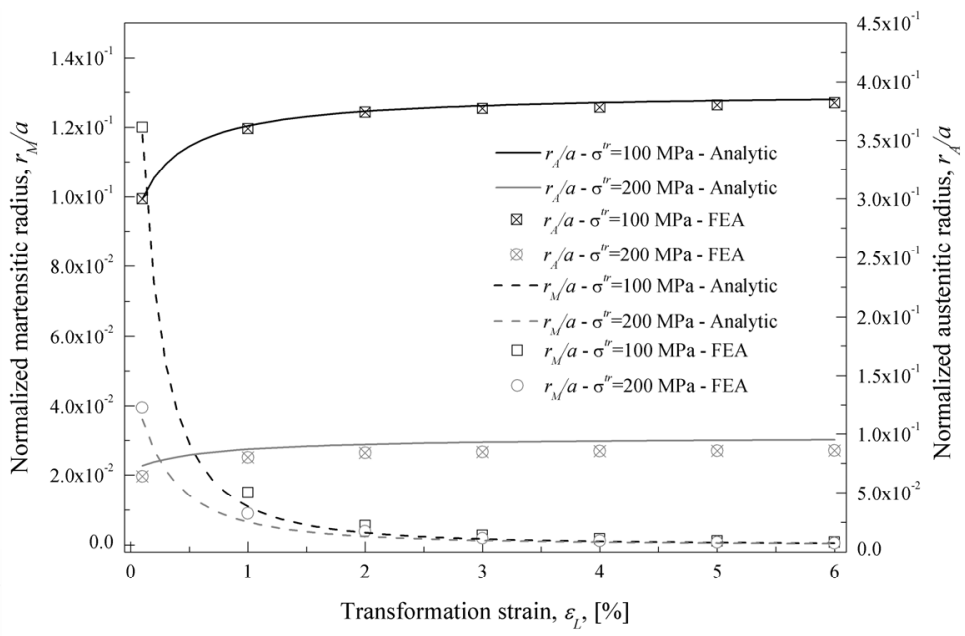

b)

Figure 4: Comparisons between analytical and FE results: a) crack tip von Mises stress and b) transformation radii as a function the transformation strain $\left(\varepsilon_{L}\right)$ and for two values of the transformation stress $\left(\sigma^{t r}=\sigma^{A M}\right)$ [23].
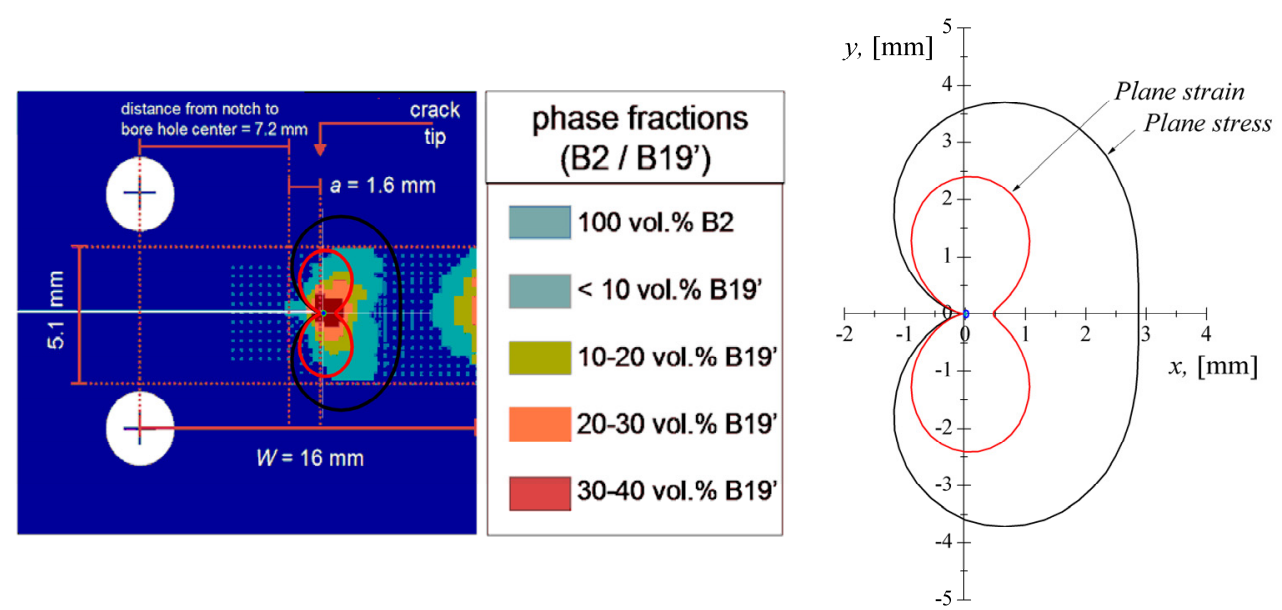

Figure 5: Comparison of the crack-tip transformation region between numerical predictions and experimental observations by synchrotron X-ray microdiffraction observations [24].

The analytical model have been also used to define possible fracture control parameters in SMAs based on the stress equations in both austenitic and martensitic region and on the definition of Stress Intensity Factor in LEFM. In particular, two different SIFs have been defined in [25]: an austenitic SIF, namely $K_{I A}$, and a martensitic or crack tip SIF, namely $K_{I M}$. In particular, the austenitic SIF, $K_{I A}$, can be directly obtained from the modified Irwin's approach described in the previous section, and it can be regarded as the effective SIF $K_{I e}$ :

$$
K_{I A}=\lim _{\hat{r} \rightarrow 0} \sqrt{2 \pi \hat{r}} \sigma_{A}=K_{I e}
$$

with $\hat{r}=r-\Delta r$; the martensitic SIF, $K_{I M}$, is given by: 


$$
K_{I M}=\lim _{r \rightarrow 0} \sqrt{2 \pi r} \sigma_{M}=\frac{2(1-v)}{2(1-v)+\left(\alpha^{-1}-1\right)} K_{I A}
$$

Eq. 12 shows that $K_{I M}$ can be expressed ad a function of $K_{I A}, v$ and of the Young's modulus ratio $\alpha$. However, it is worth noting that the knowledge of the extent of transformation region, in terms of $r_{A}$, is required to calculate both $K_{I A}$ and $K_{I M}$ and an iterative approach is required to calculate these parameters as described in [25].

Fig. 6a shows the values of $K_{I A}$ and $K_{I M}$, normalized with respect to the applied SIF $K_{I}^{\infty}=\sigma^{\infty} \sqrt{\pi a}$, as a function of the transformation strain, $\varepsilon_{L}$, and for different values of the transformation stress, $\sigma^{A M}$, for an alloy with $v=0.3$, $E_{A}=40 G P a$ and $\alpha=0.5$. Note that the same curves are used to represent $K_{I A}$ and $K_{I M}$, as $K_{I M} / K_{I A}$ is a constant depending on the elastic properties of the alloy, as shown in eq. 12. The figure illustrates that both $K_{I A}$ and $K_{I M}$ increase with increasing the transformation strain, and this effect is more evident when decreasing the transformation stress, as a direct consequence of the increase of the transformed region near the crack tip [23]. Furthermore, $K_{I A}$ is always greater than $K_{I}^{\infty}$, with $K_{I A} / K_{I}^{\infty} \rightarrow 1$ when $\sigma^{A M} \rightarrow \infty$ and $\varepsilon_{L} \rightarrow 0$, i.e. in the case of linear elastic materials. In addition, the martensitic SIF, $K_{I M}$, is always smaller than $K_{I}^{\infty}$, which indicates a reduction of the stresses at the very crack tip if compared with linear elastic materials. Fig. 6b, illustrates the effects of the testing temperature on both $K_{I A}$ and $K_{I M}$ for a commercial superelastic NiTi alloy. The figure shows that a decrease of both SIFs is observed when increasing the temperature, as a direct consequence of the increase of the transformation stress. In particular, a reduction of about $20 \%$ is observed in the temperature range between $273 \mathrm{~K}$ and $343 \mathrm{~K}$, which correspond to a range of transformation stress between about $90 \mathrm{MPa}$ and $800 \mathrm{MPa}$. However, $K_{I A}$ and $K_{I M}$ decrease rapidly from $273 \mathrm{~K}$ to $290 \mathrm{~K}$, while a small variation, i.e. of about $2 \%$, is observed when the temperature is above $290 \mathrm{~K}$. This effect is a direct consequence of the increase of the transformation stress with increasing the temperature, which causes a marked reduction of the transformation region, as discussed in [23], and, consequently, $K_{I A}$ approaches to the applied SIF $K_{I}^{\infty}$, i.e. the alloy behaves like a linear elastic material. Furthermore, it is worth noting that the temperature range is limited by a lower bound, $T_{\min }$, which corresponds to a transformation stress equal to zero, and by an upper bound $T_{\min }=M_{d}$, which represents a characteristic maximum temperature for stress induced transformation.

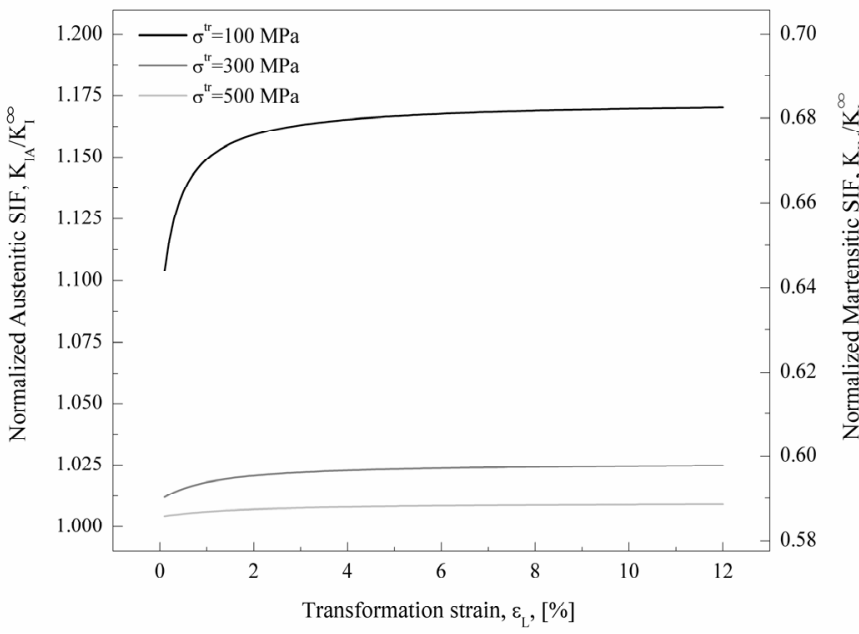

a)

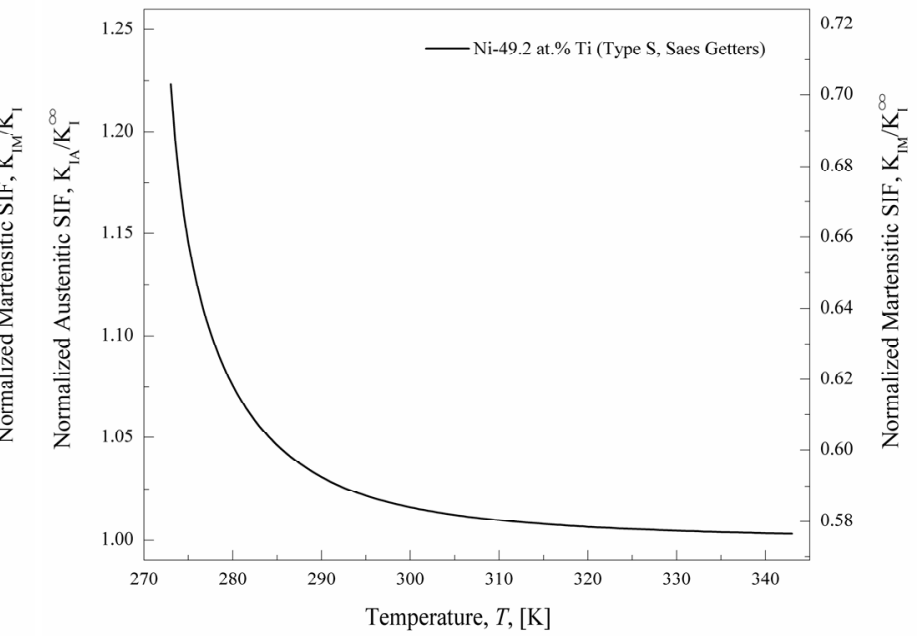

b)

Figure 6: Martensitic and austenitic SIFs, $K_{I A}$ and $K_{I M}$, normalized with respect to the applied SIF, $K_{I}^{\infty}$, as a function of: a) the transformation strain $\left(\varepsilon_{L}\right)$ and for different values of the transformation stress $\left(\sigma^{A M}=\sigma^{t r}\right)$, b) the testing temperature (T) [25].

The reference model has been recently modified in [26] to overcome one of the basic limitation, i.e. the assumption of constant stress transformation. In fact, it has been demonstrated that the slope of the stress-strain transformation plateau increases under specific loading conditions, such when increasing the loading rate or under cyclic loads [30]. To this aim, 
the stress-strain response is modeled as a tri-linear material with a generic slope of the transformation plateau. A detailed description of the modified model is out of the scope of the paper, therefore just the main results are reported and discussed here. Figs. 7 illustrate the effects of the slope of the stress-strain transformation curve on the crack tip stress distribution (Fig. 7a) and on the transformation radii (Fig. 7b) for a SMA with $E_{A}=40 G P a, \alpha=0.5$ and $\varepsilon_{L}=4 \%$. In particular, two values of the slope of the transformation plateau, with the same average value of the transformation stress $\sigma_{\text {avg }}^{A M}=\left(\sigma_{s}^{A M}+\sigma_{s}^{A M}\right) / 2=375 M P a$, are compared with the stress distribution in the case of constant transformation stress. The figures clearly illustrate a marked effect of the slope of the transformation plateau on the austenitic radius $r_{A}$, which represents the outer contour of the transformation region, while a slight effect on the martensitic radius $r_{M}$ is observed. This is expected to play a role on fracture properties of SMAs, as the outer transformation contour defines the fracture process zone and it is used to calculate the effective SIF based on the modified Irwin's correction (Eqs. 4-6).

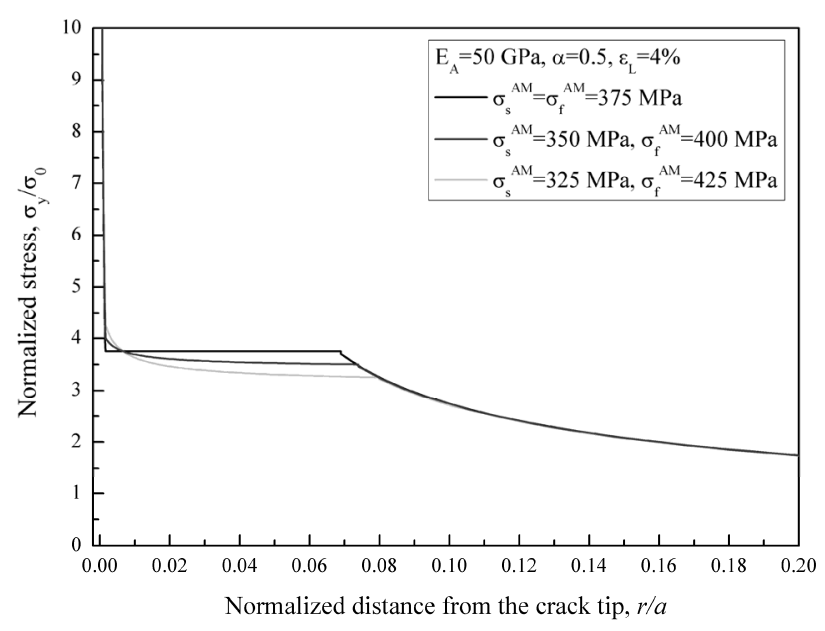

a)

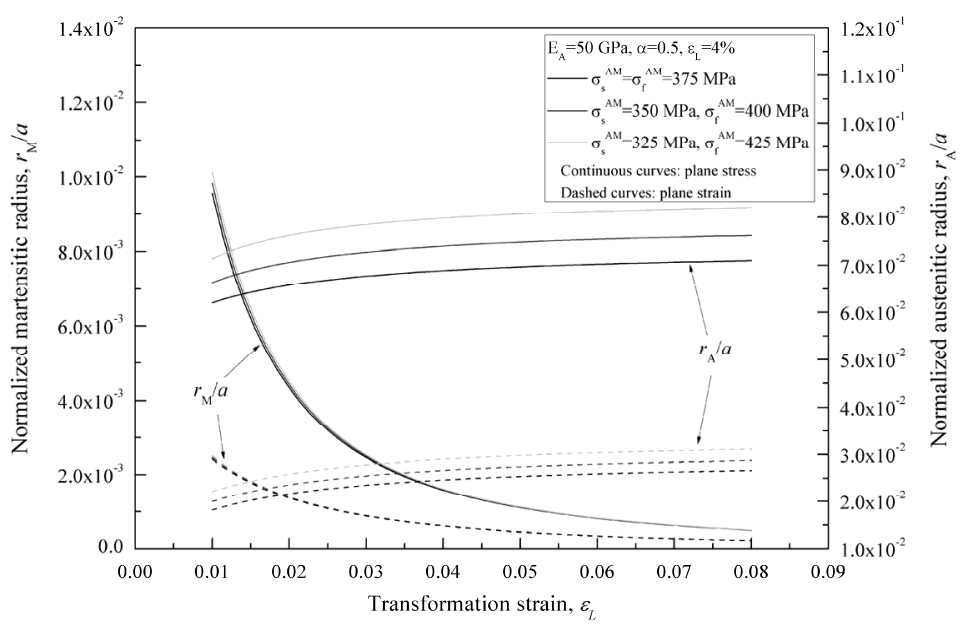

b)

Figure 7: Effects of the slope of the stress-strain transformation curve: a) crack tip stress distribution and b) transformation radii [26].

\section{EXPERimental MEASUREMENTS}

S ome experimental studies have been carried out recently to analyze the fracture response of NiTi pseudoelastic alloys, by using single edge crack specimens obtained from commercial sheets [7, 8]. In particular, the effects of Nd: YAG laser welding process on the fracture properties of a $\mathrm{Ni}$ rich $\mathrm{Ti}$ alloy have been analyzed in [7] by systematic comparison between base and laser welded materials, while the effects of testing temperature have been studied in [8].

$\mathrm{Ni}-49.2$ at. $\%$ Ti pseudoelastic sheets with thickness $t=0.75 \mathrm{~mm}$ and with a nominal austenite finish temperature $\mathrm{A}_{\mathrm{f}}=-7^{\circ} \mathrm{C}$ (Type S, Memry, USA) were used. The welding process was carried in open air conditions, by a Nd:YAG laser source (HL $2006 \mathrm{D}$ ) with a maximum power of $2 \mathrm{~kW}$, and a shielding/clamping system to avoid chemical contamination of the molten zone and the formation of hot cracks [7]. A set of preliminary tests were carried out in order to identify the optimal values of the process parameters, such as average power and welding rate. To this aim, microscopic observations and hardness tests were executed to evaluate the extension of the heat affected zone (HAZ) and molten zone (MZ), obtained by several values of the aforementioned welding parameters. Finally, the following values were chosen: average power of $850 \mathrm{~W}$ and welding rate of $2400 \mathrm{~mm} / \mathrm{min}$. Fig. 9 illustrates a comparison between the load $v s$ crack mouth opening displacement curves of the reference and laser welded materials, obtained from isothermal tests of SEC specimens, carried out at room temperature. The notch strength was calculated for a comparative analysis between the fracture resistance of the reference and the laser welded materials, according to the standard ASTM E338-91, and no further considerations have been made about the complex fracture mechanisms in SMAs. Three different specimens for each type were tested and the results are illustrated in Tab. 1; this table clearly illustrates that the welded specimens exhibit a reduction in the notch strength of about $15 \%$ with respect to the reference specimens. 


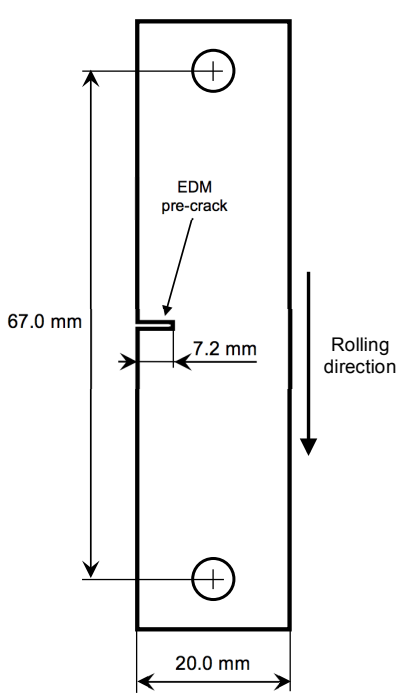

a)
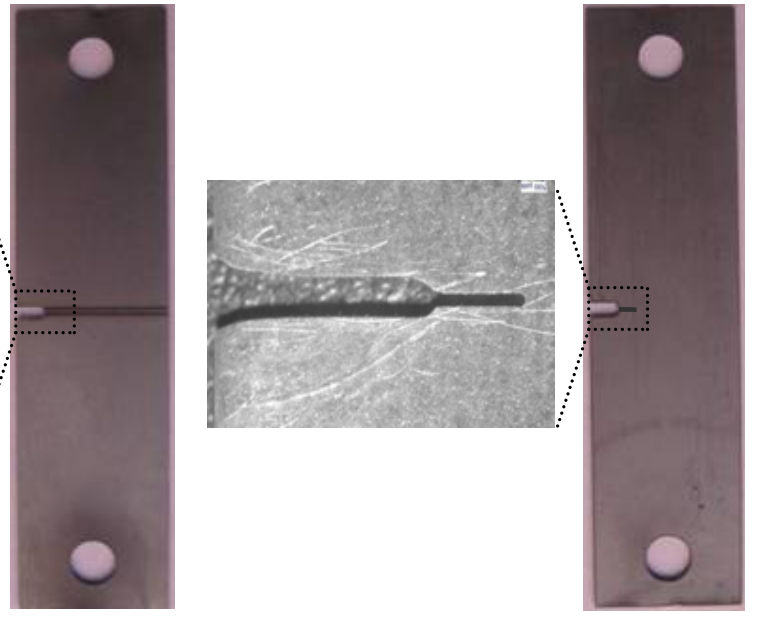

b)

Figure 8: SEC specimens for fracture tests: a) specimen geometry and b) reference and welded specimens with highlights of the precracks [7].

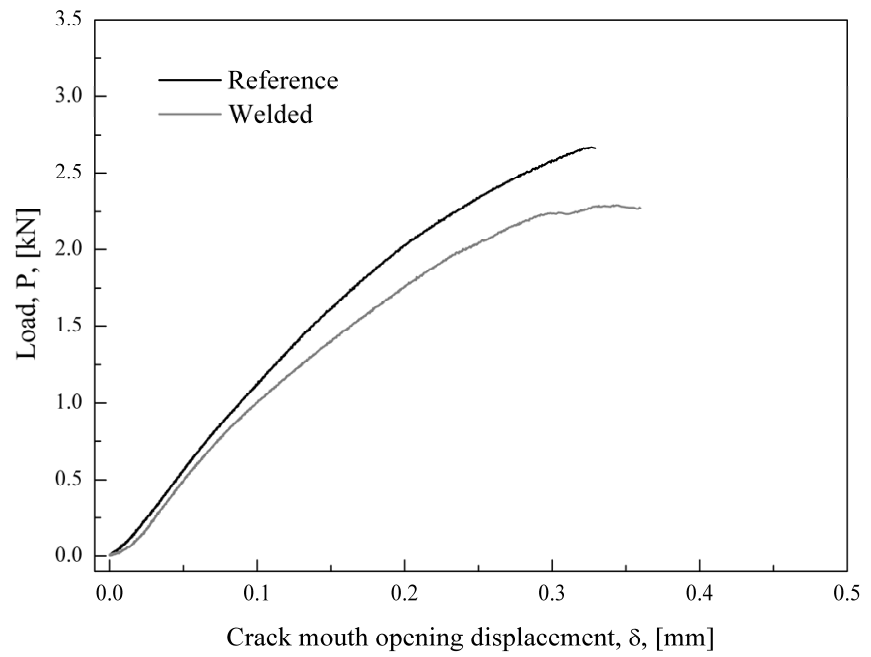

Figure 9: Comparison between the load vs Crack mouth opening displacement curves of the reference and welded specimens [7].

\begin{tabular}{ccc}
\hline Specimen type & Maximum Load & Notch strength \\
{$[\mathrm{MPN}]$} & $284 \pm 3$ \\
Reference & $2.65 \pm 0.03$ & $243 \pm 5$ \\
Welded & $2.26 \pm 0.05$ & \\
\hline
\end{tabular}

Table 1: Mechanical strength of the SEC specimens [7].

The fracture path is almost straight along the symmetry plane of both specimens and it is always located in the heat affected zone (HAZ) of the welded specimens. The fracture surfaces of the SEC specimens were analyzed by SEM investigations as illustrated in Fig. 10, which shows a comparison of the fracture surface of the reference and welded specimens. The figures indicate a ductile fracture surface in the reference material, with dimple size of about $10-30 \mu m$, while a more brittle fracture mechanism is observed in the welded specimen with dimple size of about $5 \mu \mathrm{m}$. 


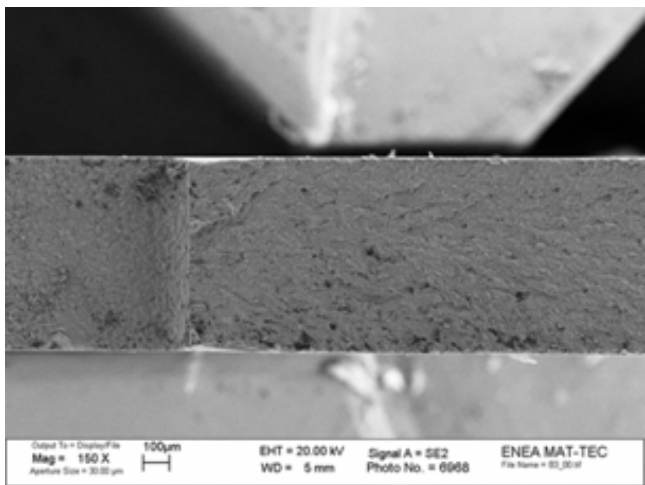

a)

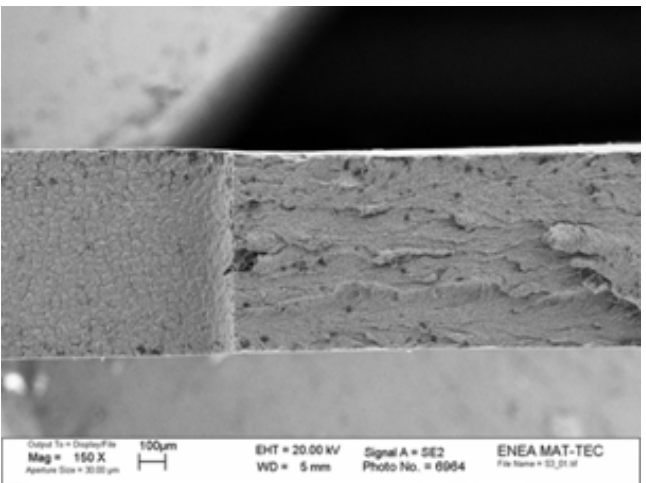

b)

Figure 10: SEM observation of the fracture surface: a) reference and b) welded specimen [7].

The effects of temperature, within the stress-induced transformation regime, in single edge crack specimens (SEC) have been recently analyzed in [8], by experimental measurements and analytical studies.

Ni-49.2 at.\% Ti pseudoelastic sheets with oxide-free surfaces and a thickness of $0.5 \mathrm{~mm}$ (Type S, Memry, USA) have been used in this investigation. Single edge crack specimens specimen, shown in Fig. 11, have been made by electro discharge machining (EDM). In particular, Fig. 11.a shows the dimensions of the specimen, while Fig. 11.b illustrates a picture of the specimen with highlights of the pre-crack. This latter was made by two subsequent steps: 1) electro discharge machining by using a copper wire $(\phi=200 \mu \mathrm{m})$ with a length of about $3 \mathrm{~mm}$ and 2) fatigue pre-crack with a length of about $0.3 \mathrm{~mm}$. Isothermal fracture tests have carried out by applying a monotonic tensile load until fracture under displacement control condition, at a crosshead speed of $0.005 \mathrm{~mm} \mathrm{~s}^{-1}$. The tests were carried out at different values of the testing temperature for $\mathrm{T}>\mathrm{A}_{\mathrm{f}}\left(\mathrm{T}_{1}=303 \mathrm{~K}, \mathrm{~T}_{2}=318 \mathrm{~K}\right.$ and $\left.\mathrm{T}_{3}=343 \mathrm{~K}\right)$ and the load-displacement curves were recorded. Finally, the mode I stress intensity factor was computed, based on LEFM theory, together with modified SIFs for SMAs, based on the reference analytical model [23].

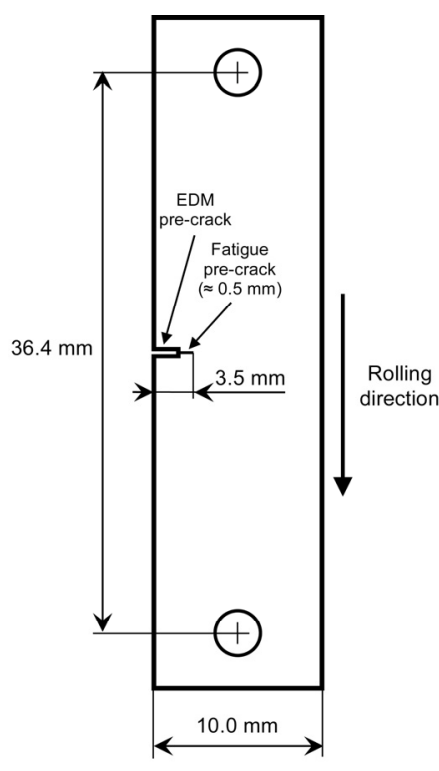

a)
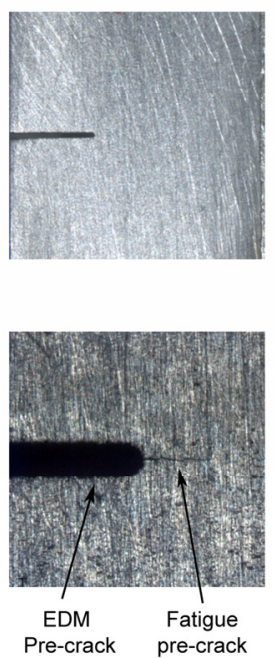

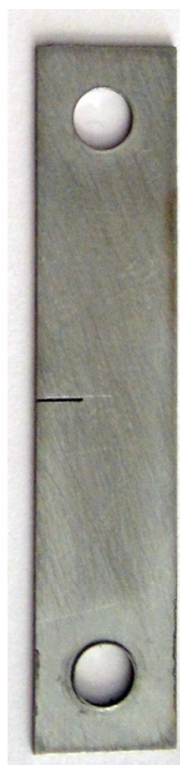

b)

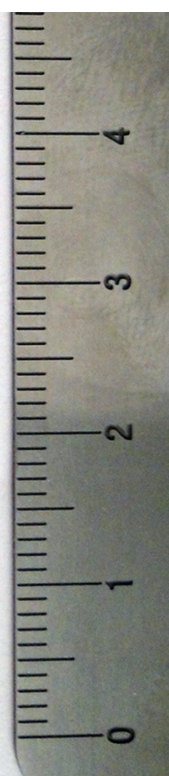

Figure 11: Single Edge Crack (SEC) specimen: a) shape and dimensions and b) picture with highlights of the pre-crack [8].

Fig. 12 illustrates the results of isothermal mechanical tests of two SEC specimens in terms applied load, $P$, and applied mode I stress intensity factor, $K_{I}^{*}$, as a function of the crosshead displacement, $d$, of the testing machine. In particular, Fig. 12a has been obtained at the temperature $T=303 \mathrm{~K}$ while Fig. $12 \mathrm{~b}$ is relative to the temperature $T=343 \mathrm{~K}$. It is worth noting that only specimens with crack length to width ratio $a / W$ between 0.3 and 0.4 have been analyzed and the applied 
stress intensity factor $\left(K_{I}^{*}\right)$ has been calculated by using literature relation for SEC specimens [29]; as a consequence $K_{I}^{*}$ is based on classical assumptions of linear elastic fracture mechanics and does not take into account the crack tip transformation mechanisms in SMAs. A qualitative comparison between Figs. 12a and 12b shows that higher non-linear effects are observed in the near peak region of the curves when decreasing the testing temperature. This effect has been observed in all SEC specimens and it can be attributed to the decrease of the transformation stresses and, consequently, to the larger size of the crack tip transformation region, when decreasing the testing temperature [23].

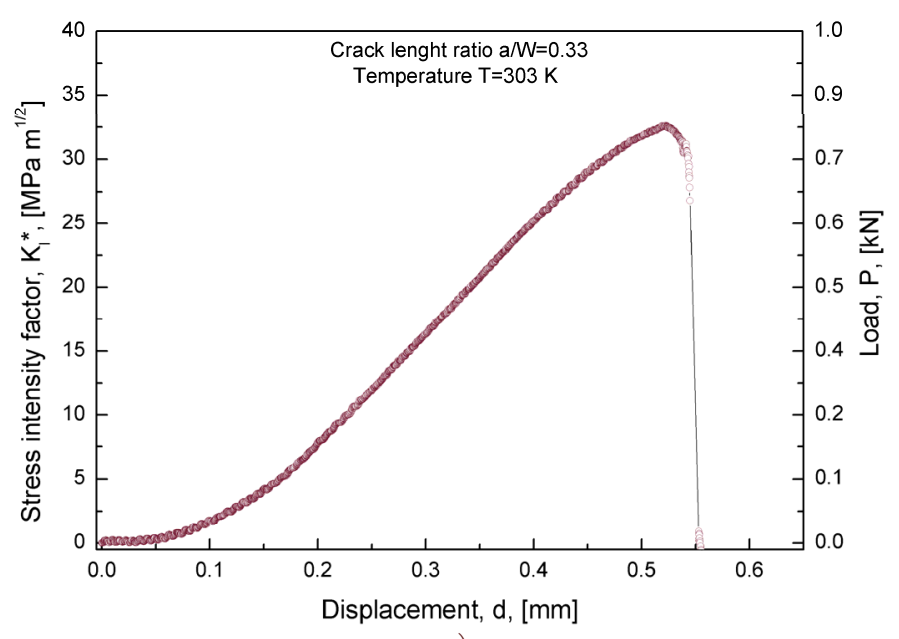

a)

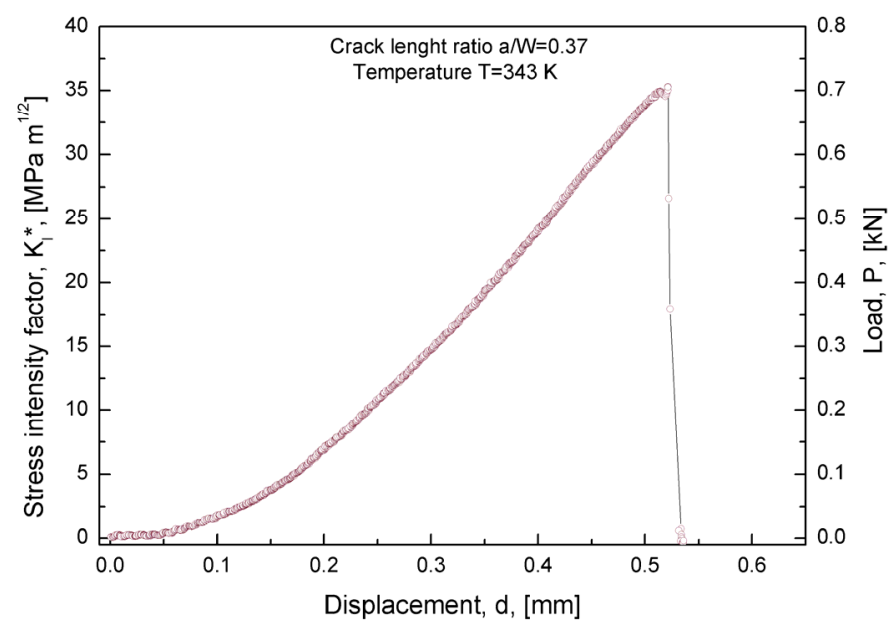

b)

Figure 12: Isothermal mechanical tests of SEC specimens in terms of applied load $(P)$ and mode I stress intensity factor $\left(K_{I}^{*}\right)$ as a function of the crosshead displacement (d): a) $T=303 \mathrm{~K}$ and b) $T=343 \mathrm{~K}$ [8].

An average value of $K_{I C^{*}}$ equal to $33.8 \mathrm{MPa} \mathrm{m} \mathrm{m}^{1 / 2}$ has been obtained in the temperature range between $303 \mathrm{~K}$ and $343 \mathrm{~K}$ and this result is very close to previous literature results [5], where a $K_{I C}{ }^{*}$ equal to $34 \mathrm{MPa}^{1 / 2}$ for a pseudoelastic alloy and $31 \mathrm{MPa} \mathrm{m} \mathrm{m}^{1 / 2}$ for a martensitic alloy have been measured. However, it is worth noting that these results cannot be directly compared as reference data have been obtained by testing miniature compact tension specimens at a fixed temperature $T=295 \mathrm{~K}$. On the contrary, the present results have been obtained for different values of the testing temperature, within the stress induced transformation regime of the alloy, which indicate an slight increase of $K_{\mathrm{IC}}{ }^{*}$, with increasing the testing temperature, from about $32 \mathrm{MPa} \mathrm{m}^{1 / 2}$ at $\mathrm{T}=303 \mathrm{~K}$ to about $35 \mathrm{MPa} \mathrm{m}^{1 / 2}$ at $\mathrm{T}=343 \mathrm{~K}$. This trend is in agreement with the predictions of the adopted analytical model, which estimate a reduction of both martensitic and austenitic stress intensity factors $\left(K_{I M}\right.$ and $\left.K_{I A}\right)$ with increasing the temperature, i.e. it indicates a toughening effect. However, further systematic studies should be carried out for a complete validation of this preliminary result, by analyzing different kind of alloys under different values of the testing temperature.

\section{CONCLUSIONS}

A bried review of the research activities on fracture mechanics of shape memory alloys (SMAs) carried out in the last few years at the Department of Mechanical Engineering of University of Calabria is illustrated. In particular, integrated approaches involving numerical simulations, analytical modeling and experimental measurements have been adopted with the aim to understand the role of crack-tip stress-induced martensitic transformation on the fracture properties of SMAs. Comparison between numerical, analytical and experimental results have been carried out and good agreements have been observed. In addition, several case studies have been analyzed in order to understand the effects of the thermo-mechanical parameters and of the loading conditions on the fracture properties of SMAs.

\section{REFERENCES}

[1] K. Otsuka, X.Ren, Prog. Mater Sci, 50(5) (2005), 511.

[2] J.H. Chen, W. Sun, G.Z. Wang, Metall Mater Trans A Phys Metall Mater Sci, 36(4) (2005), 941. 
[3] M.R. Daymond, M.L. Young, J.D. Almer, D.C. Dunand, Acta Mater., 55 (2007) 3929.

[4] S. Daly, A. Miller, A., G. Ravichandran, K. Bhattacharya, Acta Mater., 55 (2007) 6322.

[5] S. Gollerthan, M.L. Young, A. Baruj, J. Frenzel, W.W. Schmahl, G. Eggeler, Acta Mater, 57(4) (2009) 1015.

[6] S. Gollerthan, M.L. Young, K. Neuking, U. Ramamurty, G. Eggeler, Acta Mater, 57 (2009) 5892.

[7] C. Maletta, A. Falvo, F. Furgiuele, G. Barbieri, M. Brandizzi, J Mater Eng Perform, 18(5-6) (2009) 569.

[8] C. Maletta, F. Furgiuele, E. Sgambitterra, Submitted to Fatigue Fract Eng M, (2012).

[9] S.W. Robertson, R.O. Ritchie, Biomaterials, 28(4) (2007) 700.

[10] S.W. Robertson, R.O. Ritchie, J. BiomedMater. Res. Part B Appl Biomater, 84(1) (2008) 26.

[11] S.W. Robertson, A. Mehta, A.R. Pelton, R.O. Ritchie, Acta Mater, 55(18) (2007) 6198.

[12] K. Gall, J. Tyber, G. Wilkesanders, S.W. Robertson, R.O. Ritchie, H.J. Maier, Mat Sci Eng A, 486(1-2) (2008) 389.

[13] G.Z. Wang, Int J Fract, 146(1-2) (2007), 93.

[14] G.Z. Wang, F.Z., Xuan, S.T. Tu, Z.D. Wang, Mater Sci Eng A, 527 (2010) 1529.

[15] C. Maletta, A. Falvo, F. Furgiuele, A. Leonardi, J Mater Eng Perform, 18(5-6) (2009) 679.

[16] T. Baxevanis, Y. Chemisky, D.C. Lagoudas, Smart Mater Struct, 21 (9) (2012) 094012.

[17] Y. Freed, L. Banks-Sills, J Mech Phys Solids, 55 (2001) 2157.

[18] S. Yi, S. Gao, L. Shen, Int J Solids Struct, 38(24-25) (2001) 4463.

[19] F. Xiong, Y. Liu, Acta Mater, 55(16) (2007) 5621.

[20] C. Lexcellent, F. Thiebaud, Scripta Mater, 59 (2008) 321.

[21] C. Lexcellent, M.R. Laydi, V. Taillebot, Int J Fract., 169(1) (2011) 1.

[22] S. Desindes, S. Daly, Int J Solids Struct, 47 (2010) 730.

[23] C. Maletta, F. Furgiuele, Acta Mater, 58 (2010) 92.

[24] C. Maletta, M.L. Young, J Mat Eng Perform, 20(4-5) (2011) 597.

[25] C. Maletta, F. Furgiuele, Int J Solids Struct, 48(11-12) (2011) 1658.

[26] C. Maletta, Int J Fract, 177(1) (2012) 39.

[27] T. Baxevanis, D. Lagoudas, Int J Fract, 175(2) (2012) 151.

[28] G.R. Irwin, In: Proceedings of seventh Sagamore Ordnance materials conference, Syracuse University Press, Syracuse, NY, (1960) 63.

[29] P.P. Milella, Meccanica della frattura elastica e lineare. Ansaldo Nucleare, Italy (1999).

[30] C. Maletta, A. Falvo, F. Furgiuele, J.N. Reddy, Smart Mater Struct, 18 (2) (2009) 025005. 